\title{
"Informação e entretenimento para garotas de estilo e atitude": uma análise das estratégias de comunicação no Portal da revista Capricho
}

\author{
Charlene Coser Dalcol ${ }^{1}$ \\ charlenedalcol@gmail.com \\ Rejane de Oliveira Pozobon ${ }^{2}$ \\ rejane.op@terra.com.br
}

\begin{abstract}
Resumo
Este artigo consiste no estudo das estratégias de comunicação presentes no Portal da revista Capricho. A abordagem inicial se dá a partir do estudo e da classificação proposta por Stasiak (2009). Buscamos entender os processos de comunicação deste Portal com seus públicos estratégicos, uma vez que, trata-se de um exemplo multiplataforma de conteúdos autônomos, com caminhos de passagem e espaços para a participação dos internautas/ leitores. Num segundo momento observamos que a comunicação digital converte-se em um diferencial que pauta as rotinas organizacionais. Neste sentido, o trabalho de Relações Públicas apresenta-se como de fundamental importância, pois direciona os atos comunicativos, consolidando as relações da organização com seus públicos estratégicos.
\end{abstract}

Palavras-chave: Relações Públicas. Estratégias comunicacionais. Portal Revista Capricho.

\section{"Information and entertainment for girls of style and attitude: an analysis of communication strategies in portal Capricho Magazine.}

\begin{abstract}
This paper focuses on communication strategies present in the portal Capricho Magazine. The initial approach is given from the study and the classification proposed by Stasiak (2009). We try to understand the communication processes of this Portal with its strategic, since it is an example of contents autonomous platform with crossing paths and spaces for the participation of Internet users / readers. In a second step we observe that the digital communication is converted into a differential tariff organizational routines. In this sense, the work of Public Relations presents itself as extremely important, because it directs the communicative acts, consolidating the relations of the organization with its strategic public.
\end{abstract}

Key-words: Public Relations. Communication strategies. Portal Capricho Magazine.

\footnotetext{
${ }^{1}$ Relações Públicas e Mestranda do Programa de Pós-Graduação em Engenharia de Produção da Universidade Federal de Santa Maria.

${ }^{2}$ Doutora em Ciências da Comunicação. Professora Adjunta do Departamento de Ciências da Comunicação e do Programa de Pós-Graduação da Universidade Federal de Santa Maria.
} 


\section{Nota introdutória}

Este texto se propõe a mapear as estratégias comunicacionais utilizadas pelo Portal da revista Capricho, a fim de estabelecer relacionamento com o público feminino adolescente, ao qual se destina.

Dentro desta perspectiva, o entendimento da proposta deste artigo é baseado na internet como mídia digital que possibilita a construção e aplicação de estratégias de comunicação por meio do trabalho de Relações Públicas, enquanto função estratégica.

Utilizaremos o conceito de Relações Públicas apontado por Kunsch (1997) que considera a atividade como sendo mediadora do processo comunicacional nas organizações e considera a comunicação organizacional como um elemento estratégico que necessita de um profissional voltado para processos interativos e mediações, no sentido de sintonizar interesses entre organizações e públicos.

Compreende-se neste estudo a comunicação estratégica, segundo Pérez (2001), como sendo uma espécie de intencionalidade consciente e orientada para controlar os processos de comunicação e chegar aos resultados propostos, proporcionando valor significativo.

Neste sentido, Relações Públicas, enquanto gestora da comunicação, precisa estar apta a receber as tecnologias e manter bons relacionamentos com os públicos para saber reconhecer as necessidades atuais destes, planejando e desenvolvendo ações estratégicas.

O profissional de Relações Públicas desta era contemporânea funciona como agente e mediador dos fluxos de comunicação. Por meio da rede, encontram-se inúmeras oportunidades de relacionamentos que permitem uma atuação deste profissional no que tange a relação direta com os públicos de interesse.

\section{Tecnologias da Informação e da Comunicação a serviço de Relações Públicas}

Estamos vivendo em uma época e em um mundo em que as tecnologias analógicas evoluíram para as digitais. Assim, tanto as organizações como as pessoas estão mudando comportamentos, métodos e estratégias. Com isso, as organizações e todos que nela atuam participam do desafio de estarem preparados para a mudança, da exigência de novas habilidades, desempenhos, visões e estratégias e, se não responderem a tempo, a empresa terá que ser substituída por algum outro tipo de solução de negócio. 
Podemos dizer que Relações Públicas, dentro deste contexto, se apresenta como agente e mediador da comunicação e protagonista da introdução e do gerenciamento das novas dinâmicas que cada organização precisa potencializar para assumir um papel estratégico e uma postura planejada para alcançar o seu sucesso.

Segundo Oliveira (2003)

A palavra "relações", segundo Ferreira (1975), significa conhecimento recíproco e/ou convivência entre pessoas e/ ou grupos. O vocábulo "públicas" remete ao que é de uso de todos, o que é comum. Seguindo essa lógica, Relações Públicas poderia ser definida como convivência entre pessoas por meio do uso do conhecimento do que é comum a todos (!). Porém, Carlson diz que, "outros chegaram mesmo a estabelecer uma 'formula' para relações públicas: $\mathrm{R}=$ realização; $\mathrm{P}=$ publicidade; $\mathrm{R}+\mathrm{P}=$ Relações Públicas" (In Jameson, 1963, p.94). Assim, parece bastante complicado e de fato o é, pois o termo Relações Públicas tem inúmeros significados e, portanto, vários entendimentos (OLIVEIRA, 2003, p. 6).

Para Stasiak (2009, p. 60), as práticas de Relações Públicas definem o profissional de Relações Públicas contemporâneo fazendo parte de uma esfera pública totalmente descentralizada na qual a rede proporciona a superação do fluxo unidirecional ${ }^{3}$ da comunicação e oferece ao receptor um papel relevante enquanto agente e mediador da comunicação.

A publicação de Kunsch (2003) trata das dimensões da práxis de Relações Públicas e define como natureza da profissão o trabalho com os aspectos institucionais das organizações a partir de atividades específicas e uso de instrumentos e meios.

O desempenho das funções essenciais e específicas de Relações Públicas se materializa por meio da realização das correspondentes atividades profissionais. Essas atividades são inerentes ao processo de relacionamento das organizações com seus públicos e ao campo da comunicação organizacional, dentro da especificidade da comunicação institucional e da comunicação interna (KUNSCH, 2003, p.126 apud STASIAK, 2009, p. 62).

Com o advento da internet e de outras tecnologias da informação e da comunicação, as pessoas estão se comunicando em redes de escala macro, proporcionando assim, uma dinâmica que opera através de trocas comunicacionais. Assim, se constrói um espaço público compreendido como uma rede dinâmica de comunicação, informação e pontos de vista.

\footnotetext{
3 Tratamos aqui dos fluxos comunicativos propostos por Kunsch (2003, p. 84) que os divide em descendentes, ascendentes e horizontais e transversais e circulares. Essas diferenças são baseadas no modelo simétrico de duas mãos proposto por Grunig e Hunt (1984) e que tem por objetivo a busca do equilibrio entre os interesses da organização e dos públicos envolvidos com ela.
} 
Ferrari (2003) salienta,

\begin{abstract}
Neste sentido, merece ser resgatada a presença da "esfera pública" que, segundo Habermas (1984), deve ser alvo das preocupações dos profissionais de Relações Públicas por serem, hoje, espaços globais, graças à "esfera pública virtual" que permite construir relacionamentos que se expandem além das fronteiras geográficas, atingindo pessoas e localidades distantes (FERRARI, 2003, p. 7).
\end{abstract}

É justamente nesse sentido que Relações Públicas assume uma função estratégica. Ferrari (2003) destaca que o conceito de estratégia pode ser definido como habilidade comunicacional, fundamental para a prática eficaz da comunicação. A mesma autora conceitua a estratégia de forma interessante,

A palavra grega strategos refere-se a um general no comando do exército. O stratego, general da Grécia, comandava suas tropas do alto da montanha, onde também estabelecia as táticas a serem executadas. A estratégia relaciona-se às habilidades psicológicas e comportamentais que conduzem o general à definição de suas manobras (FERRARI, 2003, p. 2).

Seguindo o raciocínio da autora, para a área de Relações Públicas a estratégia se torna indispensável para garantir a qualidade dos relacionamentos da organização com seus públicos, resultando assim, na maximização dos negócios. Esta qualidade dos relacionamentos com os mais diversos públicos dependerá da competência do profissional, uma vez que, ele será o analista dos cenários que vai desenvolver e manter, de forma planejada, os relacionamentos entre os públicos, a organização e a sociedade, criando uma rede de relacionamentos com benefícios para todos os envolvidos.

\title{
3. As estratégias de comunicação no Portal da Capricho
}

O Portal da revista Capricho (www.capricho.com.br), da Editora Abril, existe desde 2008 e trata-se da versão digital da marca Capricho, que na versão impressa, é uma revista quinzenal. A Capricho foi criada em 1952, sendo primeira revista feminina do Brasil e da Editora Abril. Antigamente, seu conteúdo era constituído principalmente de fotonovelas dirigidas ao público adulto. Mais adiante, a revista foi ampliada e passou a abordar temas como: moda, beleza, comportamento, contos e variedades; contemplando assuntos de interesse das meninas adolescentes. 
Para manter-se no mercado durante tanto tempo, a revista passou por diversas reformulações: da "revista da moça moderna" para a "revista da gatinha", readequando-se ao seu público-alvo, que são meninas de 13 a 17 anos.

A partir dos estudos de Stasiak (2009, p. 87-89), pontuaremos algumas das estratégias de comunicação presentes no Portal da revista Capricho. Analisaremos alguns dos vinte e sete itens propostos pela autora, a fim de identificar que estratégias o portal já está utilizando e quais são os campos de atuação que ainda necessitam investimentos.

1. Apresentação da organização: se dá na parte superior da página, através do link Abril.com. O histórico da Capricho aparece dentro do link "Revista Capricho" que encontra-se no rodapé da página, à direita e, traz informações sobre a fundação da versão impressa da revista. Neste mesmo link encontra-se a seção "Mais sobre a Capricho", que está dividida nas subseções: "Quem somos" e "A história da Capricho". Na área "Quem somos" são apresentadas através de foto e texto ilustrativo, todas as pessoas que fazem parte da produção da revista. Em "A história da Capricho" encontra-se um breve histórico organizado por mês e ano e, ainda, algumas informações institucionais da revista como pontos fortes, objetivo, missão e características da revista impressa, tais como formato, tamanho, papel etc.

2. Pontos de identidade visual: a marca Capricho encontra-se no topo da página, atraindo as adolescentes, através da criação de um novo e diferente ambiente na internet. No canto superior direito encontramos o layout da revista na versão impressa, remetendo para a edição atual que se encontra disponível nas bancas. A cor predominante é o rosa, que vem ao encontro do que já foi dito: o Portal ser destinado ao público jovem (13 a 17 anos), especialmente feminino. Além disso, encontram-se dispostas no Portal marcas paralelas que colaboram para a identidade institucional e visual. O Portal é composto por outros 18 sites - Bottons que se encontram no rodapé da página. São eles: capricho.com.br; Loveteen; Colírios Capricho; Capricho na minha casa; Stardoll; 15 anos; SOS Cabelos; Capricha no Make; Capricho Ama; Especial Formatura; Eu amo meu corpo; Blog Diga não ao Bullying; Capricha no Vestibular; Jogos Capricho; No Capricho; Temporada de Moda; Capricho Awards e Verão Capricho. 
3. Missão e visão: a missão da Capricho é "informar, entreter, formar e conectar a maior comunidade de garotas com estilo e atitude do país". Esta informação encontra-se disponível no link "Revista", na seção "História da Capricho", e funciona de forma estratégica uma vez que, demonstra a finalidade e o significado da existência da Capricho. O conhecimento do propósito da organização, através da sua missão torna-se absolutamente essencial ao processo de gestão estratégica, pois funciona como incremento à tomada de decisões e aos próprios objetivos da organização.

4. Serviços online: existem algumas possibilidades tecnológicas de facilitação de informação ao público estratégico. Na parte central da página verifica-se a presença marcante das redes sociais como Orkut; Youtube; Twitter; Facebook; Fotolog; Tumblr; Twitpic e RSS. Ainda na página principal percebemos a presença de publicidade para a venda direta de assinaturas da revista.

No rodapé do Portal também existe uma seção específica para "promoções" que a revista oferece, ou seja, promoções oferecidas pela revista, através da participação direta das leitoras, com intuito de agregar valor à comunidade que consome a revista.

Arriscamo-nos a dizer que o Portal utiliza interessantes estratégias de comunicação, que se mostram, até então, eficazes. Porém, essas estratégias poderiam ser aprimoradas através do trabalho de Relações Públicas com os públicos estratégicos da organização no ambiente digital. Através do conhecimento exato das características destes públicos (quem são e quais as afinidades no ambiente da internet) poderiam ser construídos conteúdos comunicacionais, enxergando a comunicação digital como "alternativa" de comunicação para oportunizar agilidade na comunicação, no diálogo e no estreitamento dos relacionamentos com os públicos estratégicos.

Os processos de comunicação, hoje, tendem a possuir características diversas que vão desde a simples troca de informações, até a imersão completa em um mundo totalmente virtual, o que percebemos nitidamente no Portal analisado. Assim, podemos afirmar que o desenvolvimento das tecnologias afeta, consideravelmente, o modo com que os públicos se relacionam com as organizações e, neste contexto, Relações Públicas necessita levar isso em conta, quando da escolha de estratégias para o ambiente virtual.

Com a expansão da internet e o surgimento de um arsenal de ferramentas online abriu-se um leque de possibilidades para que um internauta publique seus próprios conteúdos e informações na 
rede. Assim, verificamos que através da atividade de Relações Públicas, no Portal da Capricho, poder-se-ia contemplar mais os canais de comunicação que tem os usuários como responsáveis pelos conteúdos, oportunizando que a organização se relacione com estes públicos sem intermediários, criando uma comunicação bilateral e uma permanente interação. Esta estratégia seria de baixo custo e, ao mesmo tempo, de confiabilidade por parte da organização, criando-se uma ferramenta de relacionamento que engajaria os stakeholders ${ }^{4}$ através de um contínuo diálogo.

Para Terra (2009) tratar-se-ia de uma dinâmica de troca de informações entre o mundo real e o virtual em que todos os participantes teriam voz. Terra (2009) contribui afirmando que a atividade de Relações Públicas precisa estar adaptada às novas realidades, proporcionando uma variedade de ferramentas que permitam o compartilhamento de informações e opiniões online.

No caso do Portal da Capricho, observamos um ambiente digital diferente, através da disposição dos conteúdos e da expansão cada vez maior da audiência. Porém, ainda seria preciso repensar o ambiente digital no sentido de criar ambientes mais estreitos e direcionados. Neste processo, o trabalho de Relações Públicas poderia assumir o papel de gestor da imagem organizacional, propondo estratégias que deponham a favor da marca Capricho, auxiliando, tanto no processo de faturamento, venda de produtos e o próprio crescimento do negócio.

Para Terra (2009) as RP modernas

(...) tem uma oportunidade única de consolidar seu potencial como disciplina líder. Além disso, é uma oportunidade de mudança em como trabalhamos: um novo tom, longe das vendas em direção a uma conversação contínua e aprendizado com os stakeholders. Os profissionais de RP devem ser advogados informados, dedicados a transmitir confiança e ouvir os públicos estratégicos ligados à organização. (TERRA, 2009, p. 4).

Através do mapeamento dos elementos estratégicos presentes no Portal da revista Capricho, acreditamos que a área de Relações Públicas, se torna indispensável para a garantia da qualidade dos processos de comunicação e do relacionamento da organização com seus públicos, para a definição de manobras necessárias na formulação de objetivos estratégicos para o ambiente digital.

Quando a comunicação está inserida no cenário das TICs, a importância estratégica está ligada, segundo Saad (2005), a um processo de inovação/ absorção das tecnologias para alavancar a comunicação humana. Para Relações Públicas um Portal na Web oferece diversas oportunidades que ultrapassam a questão espaço-temporal e ampliam a interação entre as organizações e os

\footnotetext{
${ }^{4}$ Grupos de interesse ligados diretamente à organização.
} 
públicos. Esta atividade hoje se torna importante diante das novas formas de relacionamento que as tecnologias digitais podem proporcionar. De acordo com Silva e Barichello (2006)

\begin{abstract}
O estabelecimento e a manutenção de relações, acontecimento possibilitado pela comunicação dirigida, é atualmente facilitado pelas redes digitais e internet. Essas materialidades vão além das tradicionais matérias jornalísticas impressas, releases, malas direta, folders, anúncios e campanhas publicitárias, chegam a interações, reciprocidades e apropriações, possibilitadas pelos suportes tecnológicos e digitais, nos quais os sujeitos destinatários são atuantes e determinantes da qualidade da comunicação, contribuindo para os processos de representação e reconhecimento da organização nos diferentes campos da sociedade contemporânea (SILVA e BARICHELLO, 2006, p. 10).
\end{abstract}

\title{
4. Presença da convergência de conteúdos no Portal da revista Capricho
}

Considerando que a Capricho distribui conteúdos através da utilização multiplataforma (newsletter, Twitter, blogs, Myspace, Orkut, Fotolog, Facebook, Youtube), a revista foi considerada um meio interessante a ser observado.

No site há chamadas para a leitora seguir a revista no Twitter, acompanhar os blogs, assinar a versão impressa, conhecer as matérias mais lidas, saber das enquetes, enfim, ser atraída pelo conteúdo que foram especialmente preparados para o Portal.

No Twitter são colocados posts para notícias que foram disponibilizadas recentemente no Portal. Este recurso é utilizado para divulgar notícias que acabaram de ser disponibilizadas em outras plataformas como o Portal, celular, e outras redes sociais. Exemplos de posts no Twitter são alertas enviados as seguidoras, como a informação que o perfil "coliriostwïter" não é da Capricho e, que a marca só possui um único perfil oficial.

A newsletter também funciona como plataforma, pois é encaminhada para quem se cadastrar através do Portal, sendo assinante ou não da revista. A newsletter possui diversas chamadas para conteúdos que se encontram na versão impressa e no Portal da Capricho, como forma de anunciar as leitoras os conteúdos que elas vão encontrar nessas plataformas.

De acordo com o constatado ao longo desta análise, apontamos que a convergência é um processo em andamento e que a narrativa transmidiática é a forma como a convergência de conteúdos vem ocorrendo. Ao analisar a convergência de conteúdos referente à revista Capricho, identificamos vários elementos em comum e principalmente, que a narrativa em ambientes digitais é muito semelhante.

Os exemplos da revista Capricho apontam que alguns elementos da narrativa transmidiática caminham juntos com os processos de convergência de conteúdo e que há uma oferta 
multiplataforma de conteúdos e um espaço para a participação das leitoras. Existem conteúdos comuns e ao mesmo tempo independentes nos dois principais suportes (impresso e online) que contemplam ora a mesma audiência, ora audiências diferentes.

O Portal costuma acompanhar as pautas da revista e também antecipar alguns assuntos que serão tratados na próxima edição impressa. Os chamados caminhos de transição oportunizam que o leitor caminhe de um suporte para outro de forma simples.

Desta forma, a partir da análise realizada percebemos a narrativa transmidiática, de acordo com Souza e Mielniczuk (2009, p. 14) como "um fenômeno do entretenimento da era digital que corresponde a um cenário de convergência midiática" que oferece um mesmo assunto em diversos suportes, explorando a linguagem multimídia e ampliando os relacionamentos com os públicos, permitindo que estes contribuam para a produção dos conteúdos.

\section{Considerações acerca da análise empreendida}

A partir das conceituações teóricas apresentadas e dos pontos de análise explorados, buscouse averiguar a forma como os conteúdos estão dispostos no Portal na revista Capricho a fim de entender os processos de comunicação deste com seus públicos estratégicos.

A tecnologia da comunicação e da informação é um aspecto que faz parte da constituição do Portal da revista Capricho e está diretamente ligado ao seu negócio, o que torna o Portal dinâmico e demonstra um elevado número de estratégias comunicacionais em cada seção. A comunicação estratégica do Portal para com os públicos de interesse funciona como uma espécie de intencionalidade orientada para controlar os processos de comunicação e chegar aos resultados de forma significativa, o que vem a reforçar as afirmações propostas por Pérez (2001). A comunicação estratégica funciona, então, como forma de ação em que todos os envolvidos devem participar agregando valor, diferencial competitivo e expansão tecnológica. Essa realidade é possível de ser verificada ao longo do Portal da revista Capricho.

O conceito de WebRP, desenvolvido por Stasiak (2009), mesmo não explorando todas as estratégias de comunicação possíveis no ambiente digital, demonstra a predominância de estratégias de informação e divulgação, funcionando como ferramenta para o trabalho de Relações Públicas, uma vez que estabelece um tipo de "negociação" entre os participantes do processo comunicativo, possibilitando uma maior aproximação entre a Capricho e seu público alvo e a conseqüente propagação das informações de forma rápida. 
Neste sentido, é através das estratégias de comunicação na ambiência digital que os profissionais de Relações Públicas poderão exercer suas atividades, enquanto sintonizadores de interesses, fortalecendo relacionamentos e estreitando as relações organizacionais. Ratificando Pinho (2003), a Web promove relações e se torna um verdadeiro instrumento de Relações Públicas oferecendo múltiplas possibilidades de relacionamentos que podem auxiliar, até mesmo, a construção de uma maior credibilidade organizacional.

Executar, administrar e monitorar as estratégias de comunicação na Web faz parte do papel de Relações Públicas nas organizações. Assim, a Web torna-se uma forma de gerar espaços e um meio de comunicação que proporciona interação social a serviço das trocas imediatas de informação, sem considerar as barreiras de tempo e de espaço.

Verificamos a apuração de diversos autores que nos orientam para as questões da era tecnológica e, cada vez mais, as pesquisas apontam que Relações Públicas atuam na comunicação estratégica para determinar os modos de interação empresa - públicos. Em tempos de internet, onde os fluxos de comunicação e informação se articulam de forma sinérgica e interativa, entende-se que cabe aos Relações Públicas se utilizarem desta ferramenta para dispor estratégias que agreguem valor positivo e que permitam construir um ambiente de interação e de troca de informações.

Dito isso, afirma-se que o papel de Relações Públicas na Web se materializa por meio de estratégias comunicacionais que, por um lado, proporcionam interações e relações positivas e, por outro, desvelam métodos para que, ao fim, estrategicamente, se possa afirmar os objetivos da organização, promover fluxos de interação e relação entre a organização e seus públicos no espaço virtual.

\section{Referências}

BARICHELLO, Eugenia Mariano da Rocha. Mídia, Territorialidades e sociabilidades. In: XV Encontro da Compós. UNESP, Bauru, SP, 2006. (15p.)

BARICHELLO. Eugenia. M.R, SCHEID, Daiane. Visibilidade midiática: entre estratégias das instituições e estratégias dos sujeitos. In: CONGRESSO BRASILEIRO DE CIÊNCIAS DA COMUNICAÇÃO, 30, 2007. Santos, SP. Anais. Santos: UNISANTOS.

FERRARI, Maria Aparecida. Relações Públicas, função estratégica e responsabilidade social. Revista de Estudos de Jornalismo e Relações Públicas, São Bernardo do Campo, v. 1, n. 1, p. 7-16, jun. 2003.

KUNSCH, Margarida Maria Krohling. Relações públicas e modernidade: novos paradigmas na comunicação organizacional. São Paulo: Summus, 1997. 
Integrada. $4^{\text {a }}$ ed, São Paulo: Summus, 2003.

Planejamento de Relações Públicas na Comunicação

SOUZA, Maurício Dias e MIELNICZUK, Luciana. Aspectos da narrativa transmidiática no jornalismo da revista Época. Associação Brasileira de Pesquisadores em Jornalismo. Brasîlia, nov. 2009. Disponível em: < http://www.sbpjor.org.br/sbpjor/>. Acesso em: 10 nov. 2009.

STASIAK, Daiana. Estratégias comunicacionais e práticas de WebRP: o processo de legitimação na sociedade midiatizada. Dissertação de Mestrado. Universidade Federal de Santa Maria. Santa Maria, Rio Grande do Sul, 2009.

OLIVEIRA, Ivone de Lourdes. Novo sentido da comunicação organizacional: construção de um espaço estratégico. In: Congresso Brasileiro de Ciências da Comunicação, 26., setembro de 2003. Disponível em: reposcom.portcom.intercom.org.br/dspace/bitstream/1904/4576/NP5OLIVEIRA_IVONE.pdf>.

$<\mathrm{http} / /$ Acesso em: jun. 2009.

PÉREZ, Rafael Alberto. Estrategias de Comunicación. 3 ed. Ariel Comunicação: Barcelona, 2006.

PINHO, José Benedito. Relações públicas na internet: técnicas e estratégias para informar e influenciar públicos e interesse. São Paulo, Summus, 2003.

SAAD, Beth. Comunicação digital: uma questão de estratégia e de relacionamento com públicos. Organicom: revista brasileira de comunicação organizacional e relações públicas, São Paulo: Gestcorp/Eca/Usp, ano 2, número 3, p. 94-111, $2^{\circ}$ semestre de 2005.

TERRA, Carolina Frazon. A comunicação organizacional em tempos de redes sociais online e de usuários-mídia. In: CONGRESSO BRASILEIRO DE CIÊNCIAS DA COMUNICAÇÃO, 32, 2009. Curitiba, PR. Anais... Curitiba: Universidade Positivo. 